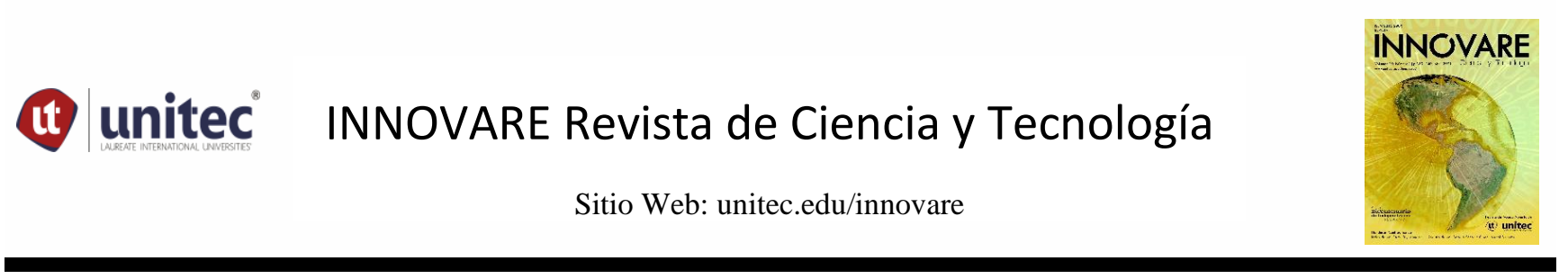

\title{
Image
}

\section{CORALBOT project: an initiative to monitor coral reefs}

Proyecto CORALBOT: una iniciativa para monitorear arrecifes de coral

José Luis Ordoñez Ávila, ${ }^{1}$ Marcial Gustavo Ordoñez Ávila, María Elena Perdomo

Carrera de Mecatrónica, Facultad de Ingeniería, Universidad Tecnológica Centroamericana (UNITEC), San Pedro Sula, Honduras
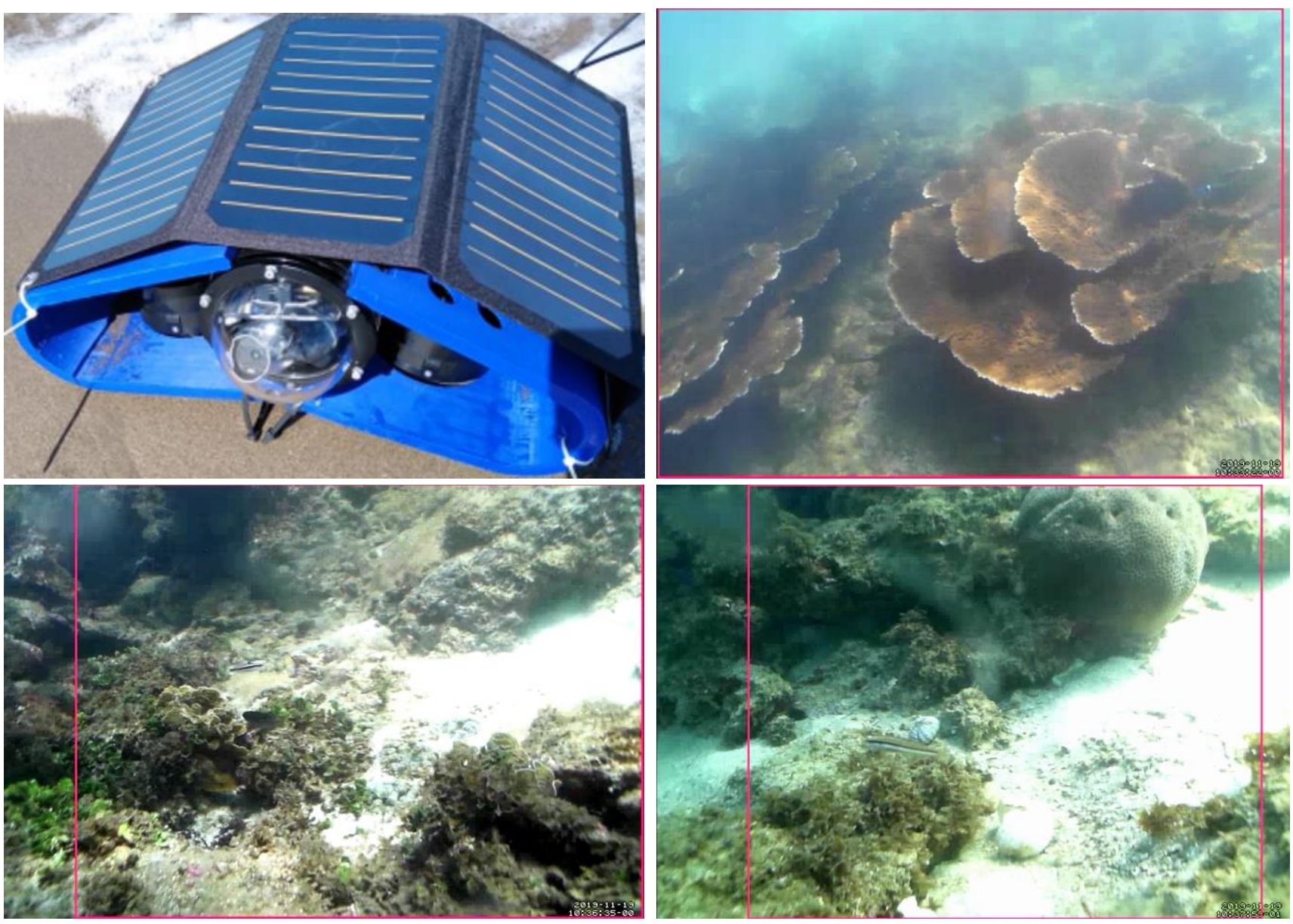

The CORALBOT project was developed in 2019, as part of the Instituto Hondureño de Ciencia, Tecnología y la Innovación (IHCIETI) applied research projects. Images show the robot's first immersion in Punta Sal, Tela, Honduras, the final robot prototype and site's coral reefs. In the future, the robot may be used to study ecosystems along the Honduran coastal shelf, as proposed by Alegría \& Pérez, (2016).

Bibliographic References. Alegría, A., \& Pérez, C. (2016). Nuevos reportes de arrecifes coralinos en el Caribe de Honduras. CEIBA, 54(2), 157-166.

\footnotetext{
${ }^{1}$ Autor corresponsal: jlordonez@ unitec.edu, Universidad Tecnológica Centroamericana (UNITEC), San Pedro Sula, Honduras

Historia del Artículo: Recibido: 8 marzo 2021; Revisado: 8 marzo 2021; Aceptado: 17 marzo 2021; Disponible en línea: 30 abril 2021

Disponible en https://doi.org/10.5377/innovare.v10i1.11413

(C) 2021 Autores. Este es un artículo de acceso abierto publicado por UNITEC bajo la licencia http://creativecommons.org/licenses/by-nc-nd/4.0
} 